\title{
Properties of Interfaced Materials and Films: Part I
}

\author{
SUFIAN M. ABEDRABBO, ${ }^{1,4,4,4}$ ANTHONY T. FIORY, ${ }^{2,7}$ \\ and NUGGEHALLI M. RAVINDRA (D) $^{3,8}$
}

\begin{abstract}
1.-Department of Physics, Experimental Solid State Physics: Semiconductors and Optoelectronics, Khalifa University, Abu Dhabi, UAE. 2.-New Jersey Institute of Technology, Newark, NJ, USA. 3.-Department of Physics, New Jersey Institute of Technology, Newark, NJ, USA. 4.-e-mail: Sufian.abedrabbo@ku.ac.ae. 5.-e-mail: sxa0215@yahoo.com. 6.-e-mail: sufiana@ju.edu.jo. 7.—e-mail: fiory@alum.mit.edu. 8._e-mail: nmravindra@gmail.com
\end{abstract}

Nature plays a significant role in the evolution of surfaces and interfaces in solids. Corrosion of metals $^{1}$ is one such example. Interfaces are ubiquitous in almost all engineered materials ${ }^{2}$ and devices $^{3,4}$ and have been known to affect the properties of interfaced materials and films. ${ }^{5}$ While the study of solid-solid interfaces represents an important and diverse area of research in materials science and engineering, ${ }^{6}$ the understanding and control $^{7}$ of interfacial morphology are critical in a number of applications including nanotechnology and energy. 8,9

Recent advancements in electronics and photonics have led to an evolution in bandgap-engineered structures as well as the choice of material candidates. ${ }^{10}$ While these structures utilize a variety of semiconductors, interfacial stress becomes an inherent issue. ${ }^{11}$ Methods that address interfacial stress and the associated strain ${ }^{12}$ as well as the chemistry, ${ }^{13}$ thermodynamics ${ }^{14}$ and roughness ${ }^{15}$ have been illustrated in a number of studies in the literature.

In general, processes such as annealing, diffusion, ion implantation, oxidation and thin/thick film deposition techniques/epitaxy are some of the methods that lead to stress/strain in solid-solid interfaces. Examples of well-studied solid-solid interfaces in the literature include $\mathrm{Si}_{-} \mathrm{SiO}_{2}{ }^{16,17}$ and Ge-Si. ${ }^{18,19}$ Recent developments in the bandgap engineering of strained monolayer and bilayer 2D materials ${ }^{20}$ make the study of interfaces and films even more interesting and challenging.

To read or download any of the papers, follow the URL http://link.springer.com/journal/11837/71/10/p age/ 1 to the table of contents page for the October 2019 issue (vol. 71, no. 10). The second part of the

Sufian Abedrabbo is the JOM advisor for the Thin Films and Interfaces Committee of the TMS Functional Materials Division. Abedrabbo, A.T. Fiory, and N.M. Ravindra are the guest editors for the topic Properties of Interfaced Materials and Films: Part I in this issue. focused topic of JOM, Properties of Interfaced Materials and Films: Part II, will be published in December 2019.

- "Antibacterial Silver Nanoparticles Supported on Graphene Oxide with Reduced Cytotoxicity" by Carolina Angulo-Pineda, Patricia Palma, Julian Bejarano, Ana Riveros, Marcelo Kogan, and Humberto Palza.

- "A 'Press and Go' Thin Biofuel Cell Patch for Power Generation" by Biao Leng, Kavya Vanamamulai, Qin Zhong, Iqbal Sherif, Nuggehalli M. Ravindra, and Zafar Iqbal.

- "Effect of Interface Structure on the Hydrophobicity, Mechanical and Optical Properties of $\mathrm{HfO}_{2} / \mathrm{Mo} / \mathrm{HfO}_{2}$ Multilayer Films" by P. Dubey, Anil K. Battu, V. Shutthanandan, and C.V. Ramana.

- "Optical and Electrical Properties of Transparent Conductive NTTO/Cu/NTTO Multilayer Films Deposited by Magnetron Sputtering” by Uang Liu, Siming Zhu, and Baokun Song.

- "Nitrogen Incorporation Induced Soft-to-Hard Transition Observed in the Mechanical Properties of Amorphous Niobium Oxide Films" by C. Orozco, O. R. Nunez, N. R. Murphy, J.G. Jones, and C.V. Ramana.

- "Strain Rate Sensitivity of the Nanoindendation Creep of $\mathrm{Ag}, \mathrm{Cu}, \& \mathrm{Ni}$ Thin Films" by Y. S. Mohammed, D.S. Stone, and A.A. Elmustafa.

- "Comparative Study on the Oxidation Behavior of Austenitic and Ferritic Heat-Resistant Stainless Steels at High Temperatures" by Yuqing Zhou, Dening Zou, Yang Pang, Tongyu Wei, Wei Zhang, Yingbo Zhang, Libo Tong, Xiang Lv, and WanWan Chen.

\section{REFERENCES}

1. C.D. Taylor, Int. J. Corros. 204640 (2012).

2. J.Y.N. Plohr, J. Thermodyn. 940385 (2011). 
3. V.Ya. Prinz, V.A. Seleznev, V.A. Samoylov, and A.K. Gutakovsky, Microelectron. Eng. 30, 439-442 (1996).

4. S. Gupta, V. Moroz, L. Smith, Q. Lu, K.C. Saraswat, and I.E.E.E. Trans, Electron. Dev. 61, 1222-1230 (2014).

5. S.Q. Wang and H.Q. Ye, Curr. Opin. Solid State Mater. Sci. 10, 26-32 (2006).

6. S. Fletcher, Aust. J. Chem. 58, 302-305 (2005).

7. N.M. Schneider, J.H. Park, J.M. Grogan, D.A. Steingart, H.H. Bau, and F.M. Ross, Nat. Commun. 8, 2174 (2017).

8. L. Martin, G. Vallverdu, H. Martinez, F. Le Cras, and I. Baraille, J. Mater. Chem. 22, 22063-22071 (2012).

9. S. Xin, Y. You, S. Wang, H.-C. Gao, Y.-X. Yin, and Y.-G. Guo, ACS Energy Lett. 2, 1385-1394 (2017).

10. C.-Z. Ning, L. Dou, and P. Yang, Nat. Rev. Mater. 2, 17070 (2017).

11. L. Angheluta, E. Jettestuen, J. Mathiesen, F. Renard, and B. Jamtveit, Phys. Rev. Lett. 100, 096105 (2008).

12. Z. Shi, E. Tsymbalov, M. Dao, S. Suresh, A. Shapeev, and J. Li, PNAS 116, 4117-4122 (2019).

13. M.P. Seah, J. Vac. Sci. Technol. 17, 16-24 (1980).

14. L. Angheluta, E. Jettestuen, and J. Mathiesen, Phys. Rev. E 79, 031601 (2009).
15. E. Kantar, D. Panagiotoulos, and E. Ildstad, IEEE Trans. Dielectr. Electr. Insul. 23, 1778-1788 (2016).

16. R.J. Jaccodine and W.A. Schlegel, J. Appl. Phys. 37, 2429 (1966).

17. N.M. Ravindra, W.N. Carr, O.L. Russo, D. Fathy, A.R. Heyd, K. Vedam and J. Narayan, in SPIE Proceedings Volume 0945, Advanced Processing of Semiconductor Devices II. (1988), pp. 84-96.

18. S. Abedrabbo, D.E. Arafah, and S. Salem, J. Electronic Materials 34, 468-473 (2005).

19. J.C. Bean, T.T. Sheng, L.C. Feldman, A.T. Fiory, and R.T. Lynch, Appl. Phys. Lett. 44, 102 (1984).

20. H.J. Conley, B. Wang, J.I. Ziegler, R.F. Haglund Jr, S.T. Pantelides, and K.I. Bolotin, Nano Lett. 13, 3626-3630 (2013).

Publisher's Note Springer Nature remains neutral with regard to jurisdictional claims in published maps and institutional affiliations. 